\title{
Inexibilidade de licitação para contratação direta de advogado
}

\author{
Unenforceability bidding for direct hiring counsel
}

Mary Silvea Santana Viera ${ }^{1}$

\section{Resumo}

\begin{abstract}
O presente artigo tem por objetivo analisar as questões relacionadas a inexigibilidade de licitação na modalidade de contratação direta de advogado. 0 primeiro item destina-se a uma análise da distinção entre a licitação dispensada, dispensável e inexigível, fazendo um confronto destes aspectos. Na sequência, busca-se analisar a inexigibilidade de licitação mais especificamente aplicada aos serviços técnicos especializados, elaborando uma análise panorâmica do assunto no Direito Administrativo, e por fim entra-se no objeto principal do presente artigo, que é a contratação direta do profissional advogado nos pequenos municípios. A parte final é destinada a ilustrar o presente assunto colacionando jurisprudências a fim de verificar como os tribunais tem se posicionado a respeito do assunto.
\end{abstract}

Palavras-Chave: Inexigibilidade de licitação. Serviços técnicos especializados. Contratação direta de advogado. Jurisprudência.

\begin{abstract}
This article aims to examine issues related to enforceability of bidding in the form of direct hiring of a lawyer. The first item is intended for an analysis of the distinction between the bid dismissed, unnecessary and unenforceable, making a comparison of these aspects. Further, it seeks to analyze the enforceability of bidding more specifically applied to specialized technical services, developing a panoramic analysis of the issue in administrative law, and finally enter into the main subject of this article, which is the direct hiring of professional attorney in small municipalities. The final part is intended to illustrate this matter collated case law to see how the courts have been positioned on the subject.
\end{abstract}

Keywords: Non-requirement of bidding. Specialized technical services. Direct hiring of a lawyer. Jurisprudence.

\section{Introdução}

${ }^{1}$ Discente do curso de Pós-Graduação em Direito do Estado - área de concentração em Direito Administrativo, da UEL - Universidade Estadual de Londrina, Paraná, 2010. 
De maneira genérica, os contratos administrativos são o acordo de vontades entre órgãos ou entidades da Administração Pública e particulares, que podem se formalizar de duas maneiras, segundo Odete Medauar (2008, p. 179) por intermédio da contratação indireta ou por meio da contratação direta.

A modalidade contratação indireta é aquela em que se faz necessária prévia realização do processo de licitação para a formalização do contrato administrativo. Tal modalidade de contratação, constituí a regra a ser adotada pelo administrador público, podendo ter como objeto a contratação de obras, serviços, compras, alienações ou mesmo servir para a concessão ou para a permissão de serviço público.

Com relação à contratação direta, essa se constitui em verdadeira exceção na Lei de Licitações e Contratos da Administração Pública, Lei 8.666, de 21 de junho de 1993. Como ressalta a referida autora, nesta hipótese, a formalização do contrato administrativo se dá sem a realização de prévio processo administrativo licitatório, sendo firmado, pelo órgão ou pela entidade da Administração, diretamente, com o particular contratado.

A contratação direta, como consigna ainda, constitui-se em gênero passível de bifurcação em duas espécies distintas: a inexigibilidade e a dispensa. A lei no 8.666, no artigo 17, incisos I e II, e no artigo 24, prevêem os casos de dispensa, no artigo 25 , os de inexigibilidade.

No decorrer do presente trabalho, analisar-se-á, as questões relacionadas à inexigibilidade de licitação na modalidade de contratação direta de advogado, fazendo um confronto entre a dispensa e a inexigibilidade de licitação. Na seqüência, busca-se analisar a inexigibilidade de licitação aplicada aos serviços técnicos especializados mais especificamente na contratação direta do profissional advogado nos pequenos municípios. Ao final a fim de ilustrar o presente assunto analisar-se-á o posicionamento de Tribunais de Justiça de alguns Estados brasileiros, bem como do Supremo Tribunal Federal, a respeito do assunto.

\section{Distinção entre Licitação Dispensada, Dispensável e Inexígivel}


$\mathrm{O}$ artigo 37, XXI, da Constituição, ao adotar a regra de exigir licitação para os contratos ali mencionados, ressalva "os casos especificados na legislação", ou seja, deixa em aberto a possibilidade de serem fixadas, por lei ordinária, hipóteses em que a licitação deixa de ser obrigatória.

A maioria dos autores pátrios promove a distinção entre licitação dispensada, dispensável e inexigível, seguindo o delineamento básico definido pela Lei no 8.666/93, inexistindo, porém, unanimidade sobre o assunto.

A principal distinção entre licitação dispensada, tratada no art. 17, e as dispensas de licitação, estabelecidas no art. 24 , repousa no sujeito ativo que promove a alienação, figurando no primeiro caso a Administração, no interesse de ceder parte do seu patrimônio, vender bens ou prestar serviços e, nos casos do art. 24, a situação é oposta, estando a Administração, como regra, na condição de compradora ou tomadora de serviços.

Outro aspecto distintivo entre licitação dispensada e dispensável é o fato de que, em princípio, na primeira não é necessário observar as formalidades do art. 26 da Lei 8.666/93, significando, com isso simplificação. Assim, conquanto esse artigo seja bom orientador para salvaguardar o gestor, não é obrigatório seu pontual acatamento, na licitação dispensada, exceto nas hipóteses reguladas pelos $\S \S 2$ e 4 으 do art. 17. Na dispensa de licitação, ao contrário, com a ressalva dos incisos I e II do art. 24, é sempre obrigatório acatar as formalidades instituídas no art. 26 da Lei de Licitações.

A lei estabelece um rol taxativo, enumerando de forma expressa as hipóteses de dispensa de licitação.

Neste sentido, as lições de Jessé Torres Pereira Júnior (2003, p. 102):

As hipóteses de dispensabilidade do art. 24 constituem rol taxativo, isto é, a Administração somente poderá dispensar-se de realizar a competição se ocorrente uma das situações previstas na lei federal. Lei estadual, municipal ou distrital, bem assim regulamento interno da entidade vinculada não poderá criar hipótese de dispensabilidade.

Vale ressaltar que, neste rol taxativo relacionado pela legislação, há a discricionariedade da Administração na escolha da dispensa ou não de licitação, devendo sempre levar em conta o interesse público. Muitas vezes, o administrador opta pela 
dispensa, posto que, como afirma Marçal Justen Filho (2001, p. 234), "os custos necessários à licitação ultrapassarão benefícios que dela poderão advir".

Em contramão, a formalização direta do contrato administrativo pela via do instituto da inexigibilidade somente será possível quando não houver a possibilidade de competição no processo licitatório. Referida situação, como ressalta Maria Sylvia Zanella Di Pietro (2002, p. 310), somente poderá ocorrer diante de duas situações: a existência de um único objeto de interesse da Administração ou, em ocasião similar, a existência de uma única pessoa dispondo de condições de atender adequadamente os seus interesses.

O artigo 25 da Lei de Licitações e Contratos Administrativos apresenta um rol exemplificativo, com isso aceita complementação, trazendo alguns casos que admitem a implementação da inexigibilidade. O referido dispositivo prevê:

Art. 25. É inexigível a licitação quando houver inviabilidade de competição, em especial:

I - para aquisição de materiais, equipamentos, ou gêneros que só possam ser fornecidos por produtor, empresa ou representante comercial exclusivo, vedada a preferência de marca, devendo a comprovação de exclusividade ser feita através de atestado fornecido pelo órgão de registro do comércio do local em que se realizaria a licitação ou a obra ou o serviço, pelo Sindicato, Federação ou Confederação Patronal, ou, ainda, pelas entidades equivalentes;

II - para a contratação de serviços técnicos enumerados no art. 13 desta Lei, de natureza singular, com profissionais ou empresas de notória especialização, vedada a inexigibilidade para serviços de publicidade e divulgação;

III - para contratação de profissional de qualquer setor artístico, diretamente ou através de empresário exclusivo, desde que consagrado pela crítica especializada ou pela opinião pública (Grifo Nosso).

Em resumo, segundo Maria Sylvia Zanella Di Pietro (2002, p. 311), a diferença básica entre as três hipóteses está no fato de que, na licitação dispensada ou dispensável, há possibilidade de competição que justifique a licitação; de modo que a lei faculta a dispensa, que fica inserida na competência discricionária da Administração. Nos casos de inexigibilidade, não há possibilidade de competição, porque só existe um objeto ou uma pessoa que atenda as necessidades da Administração; a licitação é, portanto, inviável.

\section{Da inexigibilidade de Licitação para serviços técnicos especializados}

Superada a questão da distinção entre a dispensa e a inexigibilidade, o art. 25, II, da Lei $n^{\circ}$. 8.666/93 trata da hipótese de inexigibilidade de licitação para determinados serviços 
técnicos, que possuam natureza singular, realizados com profissionais ou empresas de notória especialização. Esses serviços técnicos estão enumerados no art. 13 da Lei $n^{\circ}$. 8.666/93 e são os seguintes:

Art. 13. Para os fins desta Lei, consideram-se serviços técnicos profissionais especializados os trabalhos relativos a:

I - estudos técnicos, planejamentos e projetos básicos ou executivos;

II - pareceres, perícias e avaliações em geral;

III - assessorias ou consultorias técnicas e auditorias financeiras ou tributárias;

IV - fiscalização, supervisão ou gerenciamento de obras ou serviços;

$\mathrm{V}$ - patrocínio ou defesa de causas judiciais ou administrativas;

$\mathrm{VI}$ - treinamento e aperfeiçoamento de pessoal;

VII - restauração de obras de arte e bens de valor histórico.

Conforme o dispositivo acima transcrito, o serviço pretendido deve estar elencado no art. 13 da Lei $n$ o 8.666/93 e deve ser de natureza técnica. Sobre o assunto, vale ressaltar que o precitado dispositivo arrola serviços técnicos profissionais especializados, adjetivação essa bem mais completa do que a referida no inciso II do art. 25 , que se contenta em referilos como "serviços técnicos".

Em distinção conceitual, Hely Lopes Meirelles (2006, p. 501), com muita clareza asseriu:

Serviços técnicos profissionais são os que exigem habilitação legal para sua execução. Essa habilitação varia desde o simples registro do profissional ou firma na repartição competente até o diploma de curso superior oficialmente reconhecido. O que caracteriza o serviço técnico é a privatividade de sua execução por profissional habilitado, seja ele um mero artífice, um técnico de grau médio ou um diplomado em escola superior.

Já os serviços técnicos profissionais especializados:

são os prestados por quem, além da habilitação técnica e profissional - exigida para os serviços técnicos profissionais em geral -, aprofundou-se nos estudos, no exercício da profissão, na pesquisa científica, ou através de cursos de pósgraduação ou de estágios de aperfeiçoamento.

De acordo com J. U. Jacoby Fernandes (2008, p. 594) o art. 13 da Lei no 8.666/93, após elencar diversos tipos de serviços técnicos profissionais especializados, estabelece que, 
quando não se tratar de inexigibilidade de licitação, sejam os mesmos contratados preferencialmente mediante concurso, com estipulação prévia de prêmio ou remuneração.

É o que nos ensina o professor Adilson Abreu Dallari (2003, p. 50):

Nem todo serviço técnico especializado torna de forma pura e simples a licitação inexigível. Existem serviços que, não obstante requeiram acentuada habilitação técnica, podem ser realizados por uma pluralidade de profissionais ou empresas especializadas, indistintamente. A inexigibilidade de licitação só poderá ocorrer quando um serviço técnico se tornar singular, ou seja, quando o fator determinante da contratação for o seu executante, isto é, quando não for indiferente ou irrelevante a pessoa, o grupo de pessoas ou a empresa executante.

Nessa mesma esteira temos Marçal Justen Filho (2001, p. 175):

Os requisitos subjetivos do contratado decorrem diretamente da causa motivadora da inexigibilidade da licitação. Não se aplica o procedimento formal da licitação porque o serviço técnico-científico apresenta peculiaridades que o tornam específico, singular e inconfundível. Logo, somente particulares habilitados e capacitados poderão desenvolver o serviço de modo satisfatório. Se qualquer particular estivesse capacitado a desempenhar satisfatoriamente o serviço, não se caracterizaria ele como especializado, singular e inconfundível.

Segundo Jorge Ulisses Jacoby Fernandes (2008, p. 595): “É imperioso, contudo, que o serviço a ser contratado apresente uma singularidade que inviabilize a competição entre os diversos profissionais técnicos especializados".

$\mathrm{Na}$ verdade, a questão da singularidade reside em definição e em situação bem mais singela, a qual, indiscutivelmente, encontra-se assentada sobre um critério subjetivo do contratante. Será, desse modo, singular o serviço executado por aquele profissional cujo trabalho a Administração entenda ser o mais adequado para a solução do problema que enfrenta.

O referido autor vai mais além ensinando que a singularidade, como textualmente estabelece a lei, é do objeto do contrato, é o serviço pretendido pela Administração que é singular, e não o executor do serviço. Aliás, todo profissional é singular, posto que esse atributo é próprio da natureza humana.

A singularidade também é definida por Celso Antônio Bandeira de Mello (2008, p. 500): 
Em suma: a singularidade é relevante e um serviço deve ser havido como singular quando nele tem de interferir, como requisito de satisfatório atendimento da necessidade administrativa, um componente criativo de seu autor, envolvendo o estilo, o traço, a engenhosidade, a especial habilidade, a contribuição intelectual, artística, ou a argúcia de quem o executa, atributos, estes, que são precisamente os que a Administração reputa conveniente e necessita para a satisfação do interesse público em causa.

Referida hipótese, por si só, determina a inexigibilidade da licitação, haja vista a inviabilidade da mesma.

A própria Lei de Licitações, em seu artigo 25 , inciso II, contempla a situação, esmiuçando, no parágrafo 1으, a definição de profissional ou empresa de notória especialização:

Considera-se de notória especialização o profissional ou empresa cujo conceito no campo de sua especialidade, decorrente de desempenho anterior, estudos, experiências, publicações, organização, aparelhamento, equipe técnica, ou de outros requisitos permita inferir que o seu trabalho é essencial e indiscutivelmente o mais adequado à plena satisfação do objeto do contrato.

Diante do dispositivo acima transcrito, a notoriedade, é um requisito que deve ser verificado pelo administrador, para se caracterizar a inexigibilidade de licitação. Diante de tal fato, a pessoa jurídica ou física deve possuir algum tipo de peculiaridade na área em que atua.

Ensina, Marçal Justen Filho (2001, p. 170) alguns elementos que podem caracterizar a notoriedade, auxiliando o trabalho de análise do administrador:

Assim, a conclusão de cursos, a participação em certos organismos voltados à atividade especializada, o desenvolvimento de serviços semelhantes em outras oportunidades, a autoria de obras literárias (técnico-científicas, se for o caso), o exercício do magistério superior, a premiação por serviços similares, a existência de aparelhamento específico, a organização de equipe técnica etc.

Segundo o professor Lucas Rocha Furtado (2001, p. 90), pode ser muito subjetiva a escolha de determinada pessoa física ou jurídica, mesmo com as disposições deste permissivo legal, gerando problemas com os órgãos fiscalizadores da Administração Pública. Por isso, tal escolha deve ser devidamente justificada e motivada, a fim de que se torne legítima: 


\begin{abstract}
A fim de aferir a legitimidade da decisão adotada pelo administrador, no que diz respeito à escolha da empresa ou profissional a ser contratado sem licitação, deve ser considerada a margem de poder discricionário que a lei expressamente confere ao administrador. A não ser diante de casos em que fique flagrantemente caracterizada interpretação abusiva do art. 25 da Lei de Licitações, a escolha do contratado pelo administrador, desde que demonstrados os requisitos objetivos necessários ao enquadramento no permissivo legal, deve ser considerada legítima.
\end{abstract}

\title{
Contratação Direta de Advogado nos Pequenos Municípios
}

Entre os serviços elencados no art. 13, a um tem sido devotada, em especial, a atenção do Executivo e dos doutrinadores. Trata-se da contratação, cujo objeto se encontra elencado no inciso $V$, do seguinte teor: patrocínio ou defesa de causas judiciais ou administrativas. Para tais serviços, segundo o doutrinador Jorge Ulisses Jacoby Fernandes (2008, p. 600), dever-se-ia promover licitação na modalidade concurso, como regra.

Em regra, a contratação dos serviços jurídicos exige a habilitação legal e alguma experiência ou especialização em determinada área de atuação, sendo, portanto, amplamente encontrados no mercado.

O referido autor, em seu livro "Contratação direta sem licitação" cita um exemplo muito interessante acerca do tema: O Poder Executivo Federal, na Exposição de Motivos, interministerial, número 11/1992, tornou obrigatória a contratação, por parte do Banco Central do Brasil e entidades estatais, de empresas prestadoras de serviços técnicos profissionais de natureza jurídica, especializadas na área trabalhista, para a defesa de interesses em juízo, quando reclamadas em ações individuais, plúrimas ou coletivas na Justiça do Trabalho, sempre que houver a possibilidade de conflito entre interesses da parte dos quadros jurídicos próprios. Essa norma, contudo, não afastou a exigência do processo licitatório, que deve ser realizado mediante pré qualificação, versando no art. 114 da Lei no 8.666/93.

Com relação aos serviços advocatícios somente causas especiais devem ser contratadas por inexigibilidade de licitação. É o que também entende o professor Lucas Rocha Furtado (2001, p. 91):

A contratação de advogados para o 'patrocínio ou defesa de causas judiciais ou administrativas', como visto, depende de prévia licitação. Essa é a regra a ser seguida. Porém, se se tratar de causa judicial tão cheia de particularidades que apenas determinado profissional ou escritório, em fase de sua notória 
especialização, teria condições de defender a Administração, a contratação sem licitação seria justificada.

O primeiro passo a ser dado é verificar se a licitação é ou não exigível. No campo jurídico, o profissional do direito, enfrenta dificuldades mais ou menos complexas, afetando direito de pessoas e do próprio interesse da Administração Pública.

Vale ressaltar, que nem toda contratação direta de advogado pela Administração é correta, sendo relevante a análise do objeto contratado e se estão presentes os requisitos exigidos em lei.

Em segundo plano deve ser analisada a condição que cada município tem de manter em seu quadro uma procuradoria jurídica no porte das Procuradorias Estaduais e Federal.

No caso dos municípios especificamente, a Constituição Federal deixou ao livre arbítrio de cada administrador a disciplinar a sua estrutura administrativa, criando ou não a sua procuradoria.

Vale salientar que a maioria dos municípios pequenos não possui condições de manter em seus quadros uma procuradoria jurídica especializada, com profissionais altamente especializados por área de atuação.

A maioria das demandas dos pequenos municípios são de pequena e média complexidade e para a realização de tal tarefa basta que os advogados tenham conhecimentos gerais para os serviços diários.

Contudo, há também demandas de alta complexidade que os procuradores municipais não conseguem solucionar, não por falta de capacidade, mas sim em face ao número excessivo de processos que possuem em caráter geral.

Em casos de alta complexidade que envolvam valores elevados e que podem prejudicar ou onerar o município, os profissionais que integram o departamento jurídico não podem resolver pelos motivos já aduzidos e diante de um caso como esse, a solução está na contratação de profissional que satisfaça o interesse do Município.

Ainda, a Administração Pública deve levar em conta, que o risco de uma defesa a ser elaborada por quem não detenha uma especialização na matéria é comprometer e onerar abusivamente o patrimônio público. 
Segundo Wagner Rodolfo Faria Nogueira (2004), a contratação temporária e eventual de advogados para questões específicas não substitui os atos praticados pelos procuradores municipais. A questão a ser defendida pelo advogado contratado é incompatível com os serviços rotineiros prestados pela procuradoria municipal, visto que a matéria contratada necessita de um profissional com conhecimento diferenciado e experiência elevada no caso a ser verificado.

Salienta ainda, que ao efetuar a contratação de serviço técnico profissional de advogado, o contratante deverá verificar sua legalidade, verificando o caso específico, bem como se o contratado preenche os requisitos legais e a matéria necessita de um profissional especializado.

Outro aspecto que o referido autor destaca é que o administrador público deve observar ao contratar um advogado, se o profissional possui eficiência e eficácia no trabalho a ser realizado. Por gerir dinheiro público, o administrador terá de analisar se o seu corpo jurídico não possui condições de defender os interesses do município e verificando que não, tem o dever de contratar um profissional que possa desempenhar esta função, desde que seu preço esteja dentro dos parâmetros do mercado.

Devemos ter sempre em mente que a regra geral é sempre licitar quando diversos profissionais puderem realizar um serviço técnico. Contudo, se o produto de cada um for diferente, por características diferenciadas do autor, neste caso haverá impossibilidade de competição, dada a singularidade do serviço.

Há outro elemento que parece ser considerável para o STF na decisão do gestor público: confiança. Note-se que a literalidade da norma, ao conceituar notório especialista, permite ao gestor inferir que aquele profissional é essencial e indiscutivelmente o mais adequado a plena satisfação do objeto.

Tal posicionamento defendido pelo doutrinador Jorge Ulisses Jacoby Fernandes (2008, p. 606), resolve de forma lapidar, a difícil questão prática de ocorrência freqüente, em que o objeto é singular, porém, existe mais de um notório especialista capaz, em tese, de realizá-lo. Por isso, a opção guarda certa discricionariedade. Note-se, porém, que para ser notório especialista, nos termos da lei, é necessária a satisfação de algum dos elementos do $\S 1$ 1 do art. 25 da Lei no. 8.666/93, fato que limita a discricionariedade.

Eis parte elucidativa da ementa do Supremo Tribunal Federal no. HC 86.198-9: 
III - Habeas corpus: crimes previstos nos artigos 89 e 92 da L. 8.666/93: falta de justa causa para a ação penal, dada a inexigibilidade, no caso, de licitação para a contratação de serviços de advocacia.

1. A presença dos requisitos de notória especialização e confiança, ao lado do relevo do trabalho a ser contratado, que encontram respaldo da inequívoca prova documental trazida, permite concluir, no caso, pela inexigibilidade da licitação para a contratação dos serviços de advocacia.

2. Extrema dificuldade, de outro lado, da licitação de serviços de advocacia, dada a incompatibilidade com as limitações éticas e legais que da profissão (L. 8.906/94, art. 34, IV; e Código de Ética e Disciplina da OAB/1995), art. 7ㅇ).

(Supremo Tribunal Federal. HC 86.198-9 - Paraná. Relator: Ministro Sepúlveda Pertence. 1a Turma. Diário da Justiça, Brasília, DF, 29 jun. 2007.)

Portanto, a contratação de advogado ou escritório de advogados pela Administração Pública pela modalidade inexigibilidade de licitação é perfeitamente possível posto que o advogado exerce sua profissão de forma notória e os serviços que prestam são singulares, uma vez que restritos àqueles inscritos na Ordem dos Advogados do Brasil.

É claro que os excessos e as ilegalidades devem ser apurados, mas não podemos admitir interpretações que suprimam a possibilidade de contratação de advogados com inexigibilidade de licitação.

\section{Jurisprudências Sobre O Tema}

Segundo Adilson Abreu Dallari, se a necessidade da contratação de serviços de terceiros for ditada pela complexidade ou sofisticação do serviço desejado, a reclamar profissional ou escritório de notória especialização, a contratação direta será o caminho, com fundamento no art. 25, II, c.c. art. 13 da Lei no 8.666/93, dando-se ao $\S 1$ o do art. 25 interpretação razoável, que não inviabilize sua utilização. Para tanto, cabe anotar que a singularidade do serviço, a reclamar notória especialização do seu prestador, não significa que só possam ser assim qualificados serviços inéditos, ou que só um possa prestá-lo. Se este for o caso, haverá manifesta inviabilidade da competição, e a contratação direta terá por fundamento o próprio caput do art. 25.

Essa questão já foi objeto de decisão no Supremo Tribunal Federal. Ao relatar o RHC no 72.830-8-RO (Acórdão publicado no Boletim Licitações e Contratos - BLC, Curitiba, n 10, 1996, p. 521), o Ministro Carlos Velloso, em seu voto, acolhido por unanimidade, negando a 
existência de crime na contratação de advogado para a defesa de interesses do Estado junto aos Tribunais Superiores, fez a seguinte notável ponderação:

Acrescente-se que a contratação de advogado dispensa licitação, dado que a matéria exige, inclusive, especialização, certo que se trata de trabalho intelectual, impossível de ser aferido em termos de preço mais baixo. Nesta linha, o trabalho de um médico operador. Imagine-se a abertura de licitação para a contratação de um médico cirurgião para realizar delicada cirurgia num servidor. Esse absurdo somente seria admissível numa sociedade que não sabe conceituar valores. 0 mesmo pode ser dito em relação ao advogado, que tem por missão defender interesses do Estado, que tem por missão a defesa da res publica.

Outros julgados também foram proferidos com o mesmo fundamento:

Embora não se ponha em dúvida a capacidade profissional do advogado contratado pela Municipalidade e a necessidade de se coibir ofensas a autoridades, no exercício de suas funções, o que se vem tornando comum, em detrimento do regular Estado de Direito. Mas, não era viável prescindir-se de licitação apenas em razão do contratado ser advogado de notória especialização na área criminal, havendo que se demonstrar a necessidade técnica da Administração em contratar serviços, tendo em vista a natureza do objeto pretendido" (TJSP, 4a Câm. Cív., Ap. Cív. 188.542-1/0 - Santos, j. 2.09.93, rel. Des. Vianna Cotrim).

AÇÃO CIVIL PÚBLICA - DERSA - Contratação de escritório de advocacia - Alegada ilicitude pela ausência de licitação - Inocorrência - Notória especialização e singularidade do objeto de contratação evidenciados - Recurso improvido. (Apelação Cível n. 194.835-5/0 - São Paulo - 1ạ Câmara de Direito Público - Relator: Castilho Barbosa - 13.05.03 - V.U.)

RECURSO ESPECIAL. AÇÃO CIVIL PÚBLICA. CONTRATO PARA REALIZAÇÃO DE SERVIÇOS TÉCNICOS ESPECIALIZADOS, MAS NÃO SINGULARES. ESCRITÓRIO DE ADVOCACIA. LICITAÇÃO. DISPENSA. 1. Os serviços descritos no art. 13 da Lei $n$. $8.666 / 93$, para que sejam contratados sem licitação, devem ter natureza singular e ser prestados por profissional notoriamente especializado, cuja escolha está adstrita à discricionariedade administrativa. 2. Estando comprovado que os serviços jurídicos de que necessita o ente público são importantes, mas não apresentam singularidade, porque afetos a ramo do direito bastante disseminado entre os profissionais da área, e não demonstrada a notoriedade dos advogados em relação aos diversos outros, também notórios, e com a mesma especialidade que compõem o escritório de advocacia contratado, decorre ilegal contratação que tenha prescindido da respectiva licitação. 3. Recurso especial não-provido. (Recurso Especial n. 436869, originário do Estado de São Paulo, julgado no dia 01 de fevereiro de 2006)

LICITAÇÃO - Inexigibilidade - Caracterização - Contratação de escritório de advocacia - Critério da notória especialização - Questão que envolve avaliação discricionária da Administração na escolha do profissional ou empresa que merece sua confiança - Embargos rejeitados. (Embargos Infringentes n. 165.432-5/8 - São Paulo - 3a Câmara de Direito Público - Relator: Alvaro Lazzarini - 14.10.03 - V.U.)

EMENTA: I. Administração Pública: inexigibilidade de licitação para contratação de serviços de advocacia com sociedade profissional de notória especialização (L. 
8.666/93, art. 25, II e $\S$ 1ㅇ): o acórdão recorrido se cingiu ao exame da singularidade dos serviços contratados, que, à luz de normas infraconstitucionais e da avaliação das provas, entendeu provada: alegada violação do art. 37, caput e I, da Constituição Federal que, se ocorresse, seria reflexa ou indireta, que não enseja reexame no recurso extraordinário: incidência da Súmula 279 e, mutatis mutandis, do princípio da Súmula 636.

II. Recurso extraordinário: descabimento: falta de prequestionamento do tema do art. 22, XXVII, da Constituição Federal, de resto, impertinente à decisão da causa, fundada em lei federal. (STF, RECURSO EXTRAORDINÁRIO 466.705-3 SÃO PAULO RELATOR : MIN. SEPÚLVEDA PERTENCE (14/03/2006)).

PREFEITO MUNICIPAL - Improbidade administrativa - Contratação de escritório de advocacia sem licitação para a defesa do alcaide em ação civil pública Comprovada necessidade da contratação - Notória especialização evidenciada Escritório escolhido conforme a conveniência da administração e confiança do Chefe do Executivo Municipal - Regularidade do procedimento - Ação popular Improcedência - Recurso provido. (Apelação Cível n. 206.131-5/8-00 - Guarujá - 9a Câmara de Direito Público - Relator: Gonzaga Franceschini - 18.02.04 - V.U.).

No entanto, quando houver casos em que os serviços jurídicos de que o município necessita, não apresenta singularidade, porque se trata de matéria de caráter geral entre os profissionais da área, e não ficando evidente a notoriedade dos advogados, em relação aos outros, também notórios, e com a mesma especialidade que compõem o escritório de advocacia contratado, decorre ilegal contratação que tenha prescindido da respectiva licitação e nesse sentido o Egrégio Tribunal de Justiça de São Paulo tem decidido:

1. Prestação de serviços advocatícios. Licitação. A prestação de serviços de advocacia não está desonerada da necessidade de licitação sob pena de frustrar-se o princípio da moralidade administrativa e legitimar-se um odioso privilégio afrontoso ao Princípio de igualdade de todos perante a lei.

2. Administração. Existência de corpo de procuradores. Contratação de advogado. A existência de um corpo de servidores públicos, com atribuições para dar consultoria jurídica e proceder à defesa contenciosa da Administração, importa na exigência de que a singularidade dos serviços de advocacia se defina em questão fora de sua capacidade técnica ou se plasme de notória suspeição ou impedimento. 3. Administração. Licitação. Dispensa ou inexigibilidade. A dispensa ou inexigibilidade de licitação exige justificação escrita com (a) descrição do serviço com demonstração de sua singularidade; (b) indicação do profissional ou empresa com notória especialização, o (c) demonstração objetiva (indicação de fatos devidamente comprovados) de que o profissional ou empresa tenham reconhecida experiência por trabalhos iguais ou assemelhados, com o serviço de natureza peculiar.

(TJSP - 3. a Câm. Direito Público - Apelação Cível n.o 156.748-5/5 - Osasco - j. 24/04/01 - Relator Des. Laerte Sampaio).

AÇÃO POPULAR - Contratação de serviços de advocacia pela Administração Municipal - Pretensão de ilegalidade, imoralidade e improbidade, conflito de interesses e habilitação suficiente da Procuradoria do Município - Inadmissibilidade 
do pedido - Possibilidade do ajuste de natureza singular, sem licitação, com firma notória especialização - Aplicação da Lei 8666/93, arts. 13 e 25 - Não caracterizado prejuízo ao erário público - Demanda procedente - Recursos improvidos. (Apelação Cível n. 212.687-5/3 - Santo André - 7ạ Câmara de Direito Público - Relator: Jovino de Sylos - 06.10 .03 - V.U.).

Código: 01040 Matéria: AÇÃO POPULAR Recurso: AC 1655161 Origem: CAPIVARI Orgão: CCIV 19 Relator: LUIS DE MACEDO Data: 05/05/92 Decisão: - AÇÃO POPULAR - ATO IMPUGNADO - CONTRATAÇÃO SEM LICITAÇÃO FUNDADA EM NOTÓRIA ESPECIALIZAÇÃO - PRESTAÇÃO DE SERVIÇOS ADVOCATÍCIOS - EMPRESA SEM PERSONALIDADE JURÍDICA E PROPRIETÁRIO SEM QUALIFICAÇÃO TÉCNICA PARA O EXERCÍCIO DA ADVOCACIA - NOTÓRIA ESPECIALIZAÇÃO NÃO DEMONSTRADA - AÇÃO PROCEDENTE - SENTENÇA CONFIRMADA.

O Tribunal de Contas de Minas Gerais, em pedido de reexame à decisão do Processo no TC-375.058/95-8 de Brasília, que considerava irregular a contratação por inexigibilidade de ex-empregado aposentado para prestar serviços advocatícios na Justiça laboral de 2a Instância, negou provimento, sustentando que a Administração "não comprovou que seu trabalho era essencial e indiscutivelmente o mais adequado à plena satisfação do objeto do contrato, requisito para a contratação com base no inciso II, do art. $255^{\prime \prime}$

Com base nessa idéia, o Tribunal de Contas da União, no processo $\mathrm{n}$ 은 TC-021/2003-5, verificou a contratação, por inexigibilidade de licitação, de Escritório de Advocacia. Foram celebrados dois contratos com o escritório: o primeiro, firmado em 05/06/2002, cujo objeto era a defesa da entidade no processo administrativo junto ao CONFEA. Já o segundo, de 01/08/2002, tinha como objeto a defesa da entidade em um processo específico, e nos demais que tramitavam no TRF-1ạ Região e nos Tribunais Superiores. Diante de tal fato, o TCU decidiu:

\begin{abstract}
A diferença entre as duas contratações é que a primeira era para objeto certo e determinado, enquanto que a segunda era genérica, para todos os processos no TRF-1a Região e nos Tribunais Superiores. A jurisprudência deste Tribunal é firme no sentido de considerar irregular este último tipo de contratação direta para a prestação de serviços comuns de advocacia, agravada pelo fato do objeto ser genérico e indeterminado, uma vez que, nesses casos, não há que se falar em singularidade de objeto (Acórdão № 116/2002 - Plenário, 1691/2004 - Primeira Câmara, 1439/2003 - Primeira Câmara). A segunda contratação é indubitavelmente irregular, conforme assinala a unidade técnica.
\end{abstract}

Portanto, diante das jurisprudências acima colacionadas, pode-se concluir que a Administração Pública deverá verificar no caso concreto se o serviço técnico-científico 
apresenta nuances que o tornam específico, singular e inconfundível. E em razão disso, somente particulares habilitados e com capacidade especial poderão desenvolver o serviço de modo satisfatório.

\section{Conclusão}

A licitação dispensada, dispensável e a inexigibilidade se constituem em espécie do gênero contratação direta, permitindo que o órgão ou a entidade da Administração Pública formalize o contrato administrativo diretamente com o particular, prescindindo de prévia realização de processo de licitação.

O que definirá se a licitação pode ser dispensável, dispensada ou inexigível é a verificação da competitividade e se a mesma é viável. Nas duas primeiras, apesar de estar presente, a Administração Pública decide se valer da contratação direta. Na segunda não há qualquer possibilidade de se realizar a licitação, haja vista a inexistência da possibilidade de competição quando há um único objeto ou prestador de serviços apto a atender às necessidades da administração.

Em situações em que se identifiquem os requisitos da natureza singular do serviço prestado e pertinência com a necessidade da Administração Pública, é perfeitamente viável a contratação de serviços técnicos especializados por intermédio da inexigibilidade de licitação.

$\mathrm{Na}$ contratação de advogados, as especificidades do trabalho a ser realizado é que determinarão a exigibilidade ou não de licitação. Em se tratando de situação de contratação direta, sem licitação, deve-se verificar se o profissional se adéqua aos requisitos do objeto da contratação, como qualificação, área de atuação, experiência, confiança, entre outros requisitos.

Em síntese, não é possível formular uma afirmação genérica no tocante à exigibilidade de licitação para a contratação de serviços profissionais de advogado, seja em sentido positivo, seja em sentido negativo, pois cada caso deve ser analisado separadamente, tendo em vista que devem estar presentes alguns requisitos, estar em conformidade com o ordenamento jurídico e principalmente verificar o interesse público. 


\section{Referências}

BRASIL. Supremo Tribunal Federal. Habeas Corpus 86.198-9 - Paraná. Relator: Ministro Sepúlveda Pertence. 1ạ Turma. Diário da Justiça, Brasília, 29 jun. 2007.

. Tribunal de Contas União. Processo no TC-021.640/2003-5. Acórdão no 1.642/2004 Plenário. Relator: Ministro Ubiratan Aguiar. Diário Oficial da União, Brasília, 29 out. 2004.

DALLARI, Adílson Abreu. Aspectos jurídicos da licitação. 6. ed. São Paulo: Saraiva, 2003.

DI PIETRO, Maria Sylvia Zanella. Direito administrativo. 14. ed. São Paulo: Atlas, 2002.

FERNANDES, Jorge Ulisses Jocoby. Contratação direta sem licitação. 7. ed. Belo Horizonte: Fórum, 2008.

FURTADO, Lucas Rocha. Curso de licitações e contratos administrativos: teoria, prática e jurisprudência. São Paulo: Atlas, 2001.

INFORMATIVO de Licitações e Contratos, Curitiba, n. 33, p. 855, nov./ 1996. Processo no TC-375.058/95-8. Diário Oficial de Brasília, n. 168, 29 ago. 1996.

JUSTEN FILHO, Marçal. Comentários à lei de licitações e contratos administrativos. 8. ed. São Paulo: Dialética, 2001.

MEDAUAR, Odete. Direito administrativo moderno. 12. ed. rev. e atual. São Paulo: Revista dos Tribunais, 2008.

MEIRELLES, Hely Lopes. Licitação e contrato administrativo. 12. ed. São Paulo: Malheiros, 2006.

MELLO, Celso Antônio Bandeira de. Curso de direito administrativo. 25. ed. rev. e atual. São Paulo: Malheiros, 2008.

NOGUEIRA, Wagner Rodolfo Faria. Contratação de advogado-inexigibilidade de licitação. Revista on line Jus Vigilantibus, 2004. Disponível em <http://jusvi.com/artigos/720>. Acesso em: 24 fev. 2010.

PEREIRA JUNIOR, Jessé Torres. Comentários à lei das licitações e contratações da administração pública: lei no 8.666/93. 6. ed. Rio de Janeiro: Renovar, 2003.

Artigo recebido em:

06 de abril de 2011.

Artigo aprovado em:

28 de abril de 2011. 